\title{
Study to Assess the Effect of Counseling on Elder Abuse among Elders and Their Caregivers
}

\author{
${ }^{1}$ Gehad Mohamed Abo El Matty Shahbo, ${ }^{2}$ Bindu Bharathi, ${ }^{3}$ Annabel Lee Daoala \\ Ph.D, $M S N, B S N, R N, R M^{1}, M S N, B S N, R N, R M^{2}, M S N, B S N, R N, R M^{3}$ \\ ${ }^{1}$ Assistant Professor, Community Health Nursing, Faculty of Nursing, Port- Said University, Egypt \\ ${ }^{2}$ Faculty of Nursing, Kannur Medical College, Kerala University of Health Science, Kerala, India \\ ${ }^{3}$ Faculty of Nursing, St. Paul University, Philippines
}

\section{Introduction}

Elder abuse can be defined as "a single, or repeated act, or lack of appropriate action, occurring within any relationship where there is an expectation of trust which causes harm or distress to an older person ${ }^{1}$

Elders are suffering from physical abuse, psychological or emotional abuse, sexual abuse, financial exploitation, neglect, abandonment abuse, and even self-neglect ${ }^{1}$. Forms of physical abuse include rough handling during care giving, pinching, hitting, or slapping. Emotional abuse, which inflicts anguish, pain, or distress through verbal aggression, threats, intimidation, insults, humiliation, and harassment. More rarely, elders are sexually abused, which may include rape. Some elders are neglected due to failure by those responsible to provide food, shelter, health care or protection for a vulnerable elder. Older adults are frequently exploited through illegal taking, misuse, or concealment of funds, property, or assets of a vulnerable elder ${ }^{2-3}$.

Abuse of the elderly by caregivers is now recognized as a growing problem in the United States with the global population of older people (aged 60 and above) predicted to triple from 672 million in 2005 to almost 1.9 billion in 2050, concerns around elder abuse increasing ${ }^{4}$. Although the overwhelming majority of informal caregivers provide adequate to excellent care; reports of abuse are not uncommon and appear to be on the rise. What makes more the situation worse is that, many cases of elderly abuse are either not accurately reported or not known at all. Abuse by caregivers may be physical, emotional or financial. It may involve intentional or unintentional neglect. The motive behind financial abuse and intentional neglect, for example, is often greed. Domestic violence by a care giving spouse or intimate partner is motivated by the abuser's need to exercise power and control. Abuse by caregivers may be triggered or exacerbated by alcohol or substance abuse, or psychiatric illness ${ }^{5}$. Caregiver burnout and frustration can lead to elder mistreatment. Substance abuse by the caregiver or the patient, especially abuse of alcohol, significantly increases the risk of physical violence and neglect.

Counseling is a two- way process through which the provider helps the clients makes informed decision about their health. Counseling helps the patient explore their needs and concerns. It also helps them clarify, define, discuss and understand their feeling, make their own decision, and resolve their own problems ${ }^{6}$. Counseling for behavioral or personal problems in the family member can play a significant role in helping people to change lifelong patterns of behaviors or find solution to problems emerging from current stresses and educating older persons and caregivers about abuse, neglect, and exploitation to reduce elderly abuse ${ }^{7}$.

Community Health Nurses are involved in primary, secondary, and tertiary prevention efforts for elders and caregivers. Four major areas in which Community Health Nurses play an important role in addressing elder abuse are identification of suspected cases; reduction of risk and maintenance of independence; oversight, supervision, and encouragement of caregivers; and development of support group ${ }^{8}$.

Community Health Nurses should become involved in exploring service options for elderly individuals and in educating the general public in the problems of older individuals and their caregivers. These goals can be partly accomplished by designing and delivering educational programs to community groups and organizations or by advocating for legislation designed to assist elder independence and elder caregivers whenever possible. Public understanding about the ageing process and safeguards to ensure a safe and secure environment for the senior members of our communities will go a long way toward reducing the problems of elder abuse ${ }^{9}$.

Educating people about elder abuse, promoting increased social contact and support for families with dependent older adults, and encouraging counseling and treatment to cope with personal and family problems that contribute to abuse is the cornerstone of preventing elder abuse. So, the study aims to assess the effect of counseling on elder abuse among elders and their caregivers ${ }^{7}$.

\subsection{Statement Of The Problem}

Study to assess the effect of counseling on elder abuse among elders and their care givers at selected urban and rural areas of Egypt. 


\subsection{Aim Of The Study}

This study aimed to assess the effect of counseling on elder abuse among elders and their caregivers.

\subsection{Objectives}

1. To identify the socio-demographic data of elders and their care givers

2. To identify the common abuses among elders

3. To assess the level of knowledge on elder abuse among caregivers of elderly

4. To determine the effect of counseling on elder abuse between rural and urban areas of elders and their caregivers

5. To find out the association between the level of knowledge and socio-demographic variables of the elders and their care givers.

6. To find out the association between types of abuses and socio-demographic variables

\subsection{Research Approach}

\section{Research Methodology}

Quantitative research approach was adopted in this study.

\subsection{Research Design}

Quasi-experimental design with one group Pre test - Post test design was used to compare the effect of counseling on elder abuse among rural and urban elders and their care givers of Egypt between pre and post test groups. The design used was depicted below

$\mathrm{O}_{1} \times \mathrm{O}_{2}$

Pre Test $\left(\mathbf{O}_{1}\right)$ - Assessment of the level of knowledge on health problems of elderly and elder abuse among elders and their care givers before counseling.

Intervention (X) - Counseling on Elder Abuse. Which includes counseling sessions and sessions of lecture cum discussion on ageing, age related changes, health needs and problems, elder abuse, and its prevention and management. The Investigators explained above mentioned areas with the help of different instructional aids. The duration of the class was one hour.

Post Test $\left(\mathbf{O}_{2}\right)$ - Assessment of level of Knowledge on health problems of elderly and elder abuse among elders and their care givers after counseling.

\subsection{Variables}

Dependent Variable - Level of knowledge on health problems of elderly and elder abuse among elders and their caregivers

Independent Variable - Counseling sessions on Elder abuse and its management and prevention. Which includes lecture cum discussion on ageing, age related changes, health needs and problems of elders.

\subsection{Setting of the Study$$
\text { Port - Said Governorate } \rightarrow \text { E1 Arab } \rightarrow \text { Al Garabia, Egypt }
$$

2.5 Population

\subsection{Sample and sampling Technique}

A multistage random sampling technique was used to select the settings. 30 houses of elderly from the rural and urban areas were selected by simple random sampling technique.

Sample size was 60: 30 elders and their care givers from rural areas and 30 elders and their care givers from urban areas.

\subsection{Inclusion Criteria}

- Elderly 65 years and above

- Willing to participate in this study

- Able to talk and hear.

- Available at the time of data collection

\subsection{Exclusion criteria}

- Elders who were demented, delirious, disoriented and mentally challenged

\subsection{Research Tools for data collection}

The data was collected by the use of following tools:

Tool (1) - Elder Assessment Instrument (EAI) Scales: 
(2) Structured Interview Schedule:

(A) Socio-demographic data of elderly

(B) Ageing process and health problems

(C) Socio-demographic data of Caregivers

(D) Knowledge on Elder abuse

\subsection{Data collection Process}

Written permission was obtained form the administrators of the City. The consent of the chairman of city and village were obtained for this study. Also the consent of the cleric was obtained. The consent was taken from elders and their caregivers where the aim and the nature of the study were explained to them. Before and after counseling program the data was collected from the elders and their care givers with the help of interview schedule and Elder Assessment Instrument scale. Data collection for this study was carried out in the period from April 2012 to September 2012.

\section{Figures And Tables}

Table I. Distribution of Sample Based on socio-demographic variables

\begin{tabular}{|c|c|c|c|c|}
\hline \multirow{2}{*}{$\begin{array}{l}\text { Socio-demographic } \\
\text { characteristics }\end{array}$} & \multicolumn{2}{|c|}{ Group I (Rural) (n=30) } & \multicolumn{2}{|c|}{ Group II(Urban) $(n=30)$} \\
\hline & No. & $\%$ & No. & $\%$ \\
\hline $\begin{array}{l}\text { Gender: } \\
\text { Male } \\
\text { Female }\end{array}$ & $\begin{array}{l}16 \\
14\end{array}$ & $\begin{array}{l}53.3 \\
46.7\end{array}$ & $\begin{array}{c}9 \\
21\end{array}$ & $\begin{array}{l}30.0 \\
70.0\end{array}$ \\
\hline $\begin{array}{l}\text { Marital status: } \\
\text { Single } \\
\text { Married } \\
\text { Widow } \\
\text { Divorced }\end{array}$ & $\begin{array}{c}2 \\
18 \\
8 \\
2\end{array}$ & $\begin{array}{c}6.7 \\
60.0 \\
26.7 \\
6.7\end{array}$ & $\begin{array}{c}0 \\
12 \\
18 \\
0\end{array}$ & $\begin{array}{c}0 \\
40.0 \\
60.0 \\
0\end{array}$ \\
\hline $\begin{array}{l}\text { Occupation: } \\
\text { Unemployed } \\
\text { Farmer } \\
\text { Worker } \\
\text { Employee }\end{array}$ & $\begin{array}{l}15 \\
2 \\
8 \\
5\end{array}$ & $\begin{array}{l}50.0 \\
06.7 \\
26.6 \\
16.7\end{array}$ & $\begin{array}{c}21 \\
4 \\
0 \\
5\end{array}$ & $\begin{array}{c}70.0 \\
13.3 \\
0 \\
16.7\end{array}$ \\
\hline $\begin{array}{l}\text { Past history of diseases: } \\
\text { Hypertension } \\
\text { Diabetes } \\
\text { Heart diseases } \\
\text { Chest diseases }\end{array}$ & $\begin{array}{l}18 \\
4 \\
6 \\
5\end{array}$ & $\begin{array}{l}60.0 \\
13.3 \\
20.0 \\
16.7\end{array}$ & $\begin{array}{l}17 \\
10 \\
7 \\
6\end{array}$ & $\begin{array}{l}56.7 \\
33.3 \\
23.3 \\
20.0\end{array}$ \\
\hline
\end{tabular}

This table depicts that $53.3 \%$ of the samples were male in rural areas, while $70 \%$ of the subjects were females in urban areas. $60 \%$ of the subjects were married in rural areas but $60 \%$ of the subjects were widows in urban areas. $50 \%$ of the subjects are unemployed in rural area but very few of them are employed in both areas. $60 \%$ of the subjects have the history of hypertension in rural areas and $33.3 \%$ of the urban samples are suffered from diabetes.

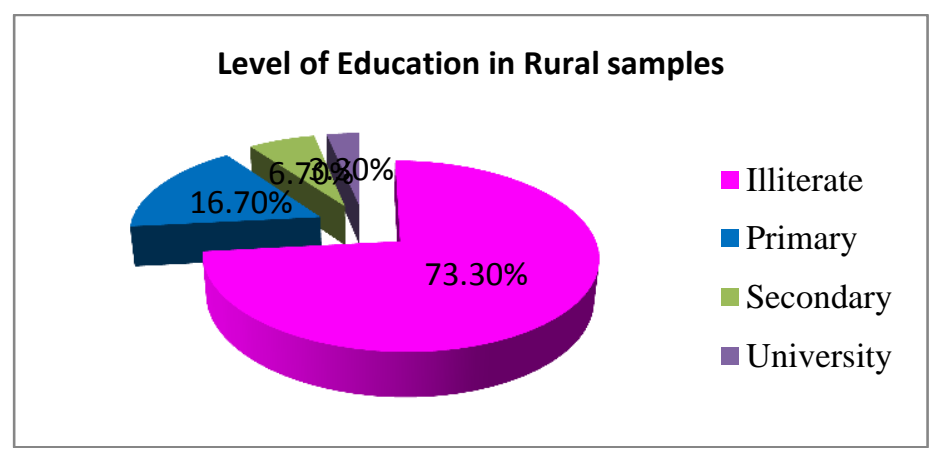




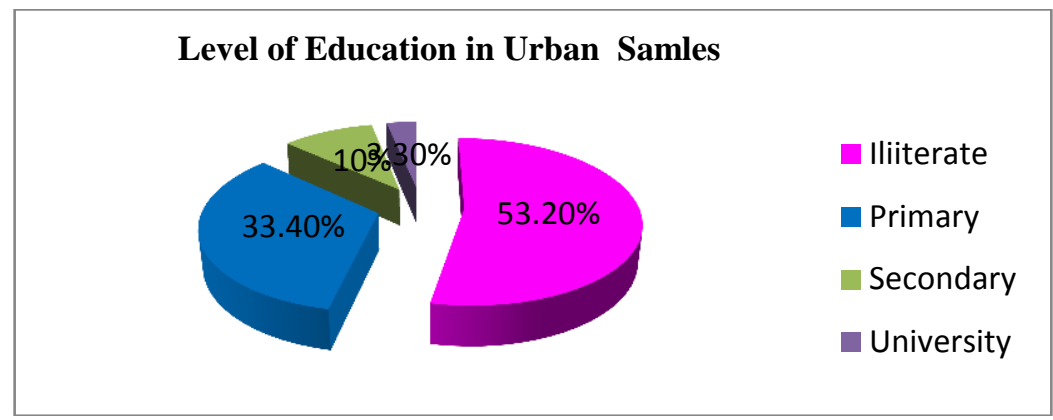

Figure 1. Distribution of Sample Based on Level of Education among rural and urban subjects

Figure 1 depicts that $73.3 \%$ of the samples were illiterate in rural areas but $53.2 \%$ of the subjects were illiterate in urban areas.

Table 2: Distribution of Sample Based on socio-demographic Characteristics of care givers

\begin{tabular}{|c|c|c|c|c|}
\hline \multirow{2}{*}{ Socio-demographic characteristics } & \multicolumn{2}{|c|}{ Group I (Rural) (n=30) } & \multicolumn{2}{|c|}{ Group II( Urban) (n=30) } \\
\hline & No. & $\%$ & No. & $\%$ \\
\hline Gender: & & & & \\
\hline$\overline{\text { Male }}$ & 0 & 0 & 6 & 20 \\
\hline Female & 30 & 100 & 24 & 80 \\
\hline Marital status: & & & & \\
\hline Single & 3 & 10 & 3 & 10 \\
\hline Married & 25 & 83.3 & 26 & 86.7 \\
\hline Widow & 1 & 3.3 & 0 & 0 \\
\hline Divorced & 1 & 3.3 & 1 & 3.3 \\
\hline Occupation: & & & & \\
\hline Unemployed & 21 & 70 & 13 & 43.3 \\
\hline Farmer & 1 & 3.3 & 0 & 0 \\
\hline Worker & 0 & 0 & 1 & 3.3 \\
\hline Employed & 8 & 26.7 & 16 & 53.3 \\
\hline Education: & & & & \\
\hline Illiterate & 10 & 33.3 & 6 & 20 \\
\hline Primary education & 4 & 13.3 & 2 & 6.7 \\
\hline Secondary education & 9 & 30 & 7 & 23.3 \\
\hline University & 7 & 23.3 & 15 & 50 \\
\hline
\end{tabular}

Table 2 shows that $100 \%$ of care givers are females in rural areas but $20 \%$ of care givers are males in urban areas. $83.3 \%$ of the care givers are married in rural areas while $10 \%$ of the care givers are single in urban areas. $70 \%$ of the care givers are unemployed in rural areas where as $53.3 \%$ of the care givers are employers in urban areas. $33.3 \%$ of the care givers are illiterate in rural areas but $50 \%$ of the care givers are undergone University education in urban areas.

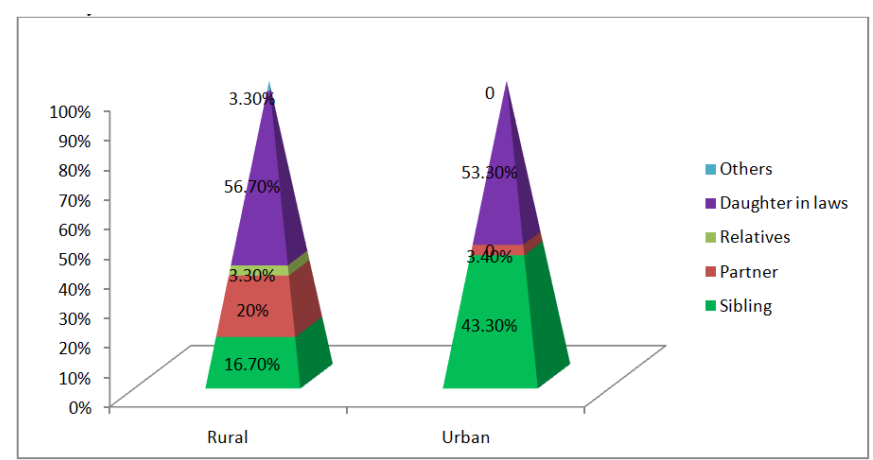

Figure 2: Distribution sample based on Relationships of Caregivers

This figure depicts that more than half of the care givers are daughter in-laws of both urban and rural areas. 
Table 3: Distribution of Sample Based on history of disease

\begin{tabular}{|c|c|c|c|c|}
\hline \multirow{2}{*}{$\begin{array}{l}\text { Socio-demographic } \\
\text { characteristics }\end{array}$} & \multicolumn{2}{|c|}{ Group I (Rural) $(n=30)$} & \multicolumn{2}{|c|}{ Group II( Urban) $(n=30)$} \\
\hline & No. & $\%$ & No. & $\%$ \\
\hline Past history of diseases: & & & & \\
\hline$\overline{\text { Diabetes }}$ & 4 & 13.3 & 1 & 3.3 \\
\hline Hypertension & 4 & 13.3 & 3 & 10 \\
\hline Past history of surgery: & & & & \\
\hline$\overline{\text { Yes }}$ & 8 & 26.7 & 7 & 23.3 \\
\hline No & 22 & 73.3 & 23 & 76.7 \\
\hline
\end{tabular}

This table depicts that $13.3 \%$ of the care givers have Hypertension and Diabetes in rural areas, but only $10 \%$ of the care givers have hypertension in the urban areas.

\section{Effect Of Counseling On Prevention Of General Problems Among Rural And Urban Elderly}

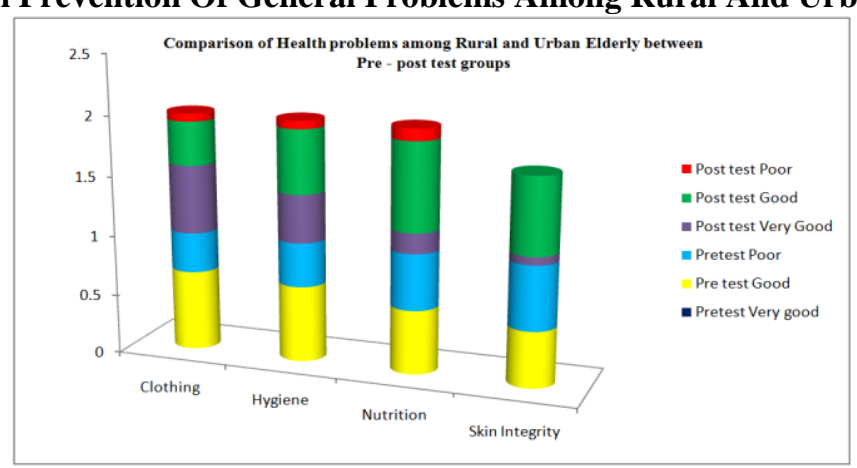

Figure 3. Comparison of Health Problems among Rural elderly between pre - post test groups

This figure shows that $33.3 \%$ have poor clothing, $36.7 \%$ have hygiene problems, $46.7 \%$ have problems of nutrition $53.3 \%$ problems of skin integrity among rural elderly during pre test but during post test they have good nutrition status $(73.3 \%)$ and good skin conditions $(63.3 \%)$.

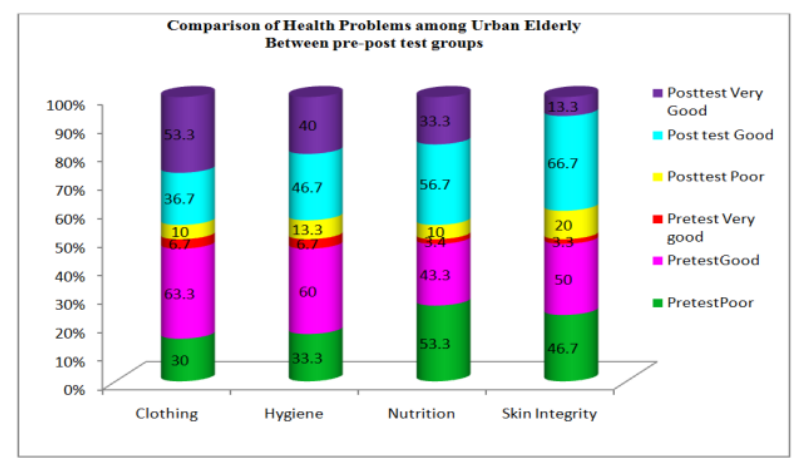

Figure 4. Comparison of Health Problems among Urban Elderly between pre - post test groups

This figure shows that $30 \%$ have poor clothing, $33.3 \%$ have poor hygiene, $53.3 \%$ have problems of nutrition $46.7 \%$ have skin problems among urban elderly during pre test but during post test they have good nutrition status $(56.7 \%)$ and good skin conditions $(66.7 \%)$.

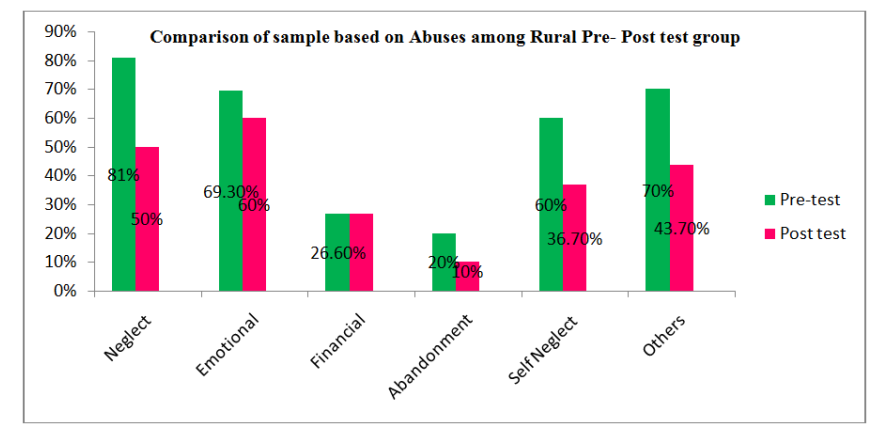

Figure5: Comparisons of abuses among rural elderly between pre and post test groups 
This figure explains that $81 \%$ of the subjects are suffering from neglect $69.3 \%$ have emotional problems $26 . \%$ are victims of financial abuse during pre test but $36.7 \%$ have self neglect $10 \%$ have abandonment during post test.

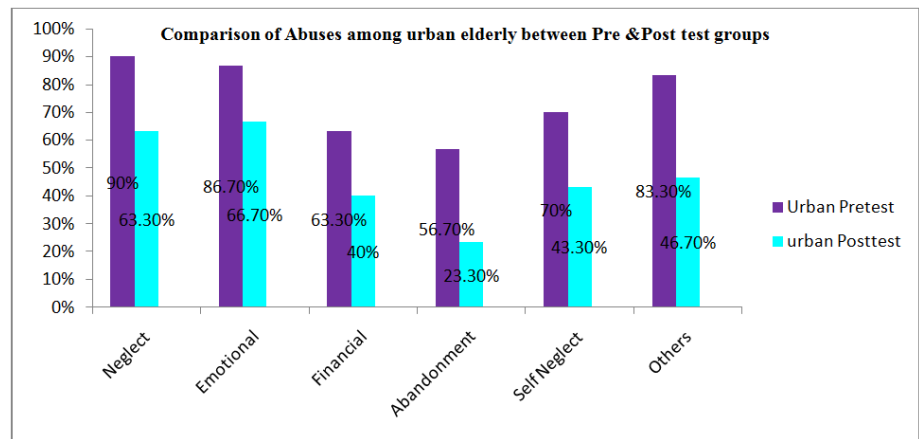

Figure 6: Comparison of Abuses among urban elderly between pre and post test groups

This figure depicts that $90 \%$ of the subjects are suffering from neglect $86.7 \%$ have emotional problems $63.3 \%$ are victims of financial abuse during pre test but $43.3 \%$ have self neglect $46.723 .3 \%$ have abandonment during post test among urban elderly.

Table: 4 Effect of Counseling on Level of Knowledge among Rural and Urban Samples

\begin{tabular}{|c|c|c|c|c|c|c|c|c|}
\hline \multirow{3}{*}{ Knowledge of Elderly } & \multicolumn{4}{|c|}{ Group I(Rural) n=30 } & \multicolumn{4}{|c|}{ Group II(Urban)n=30 } \\
\hline & \multicolumn{2}{|c|}{ Pre } & \multicolumn{2}{|c|}{ Post } & \multicolumn{2}{|c|}{ Pre } & \multicolumn{2}{|c|}{ Post } \\
\hline & No. & $\%$ & No. & $\%$ & No. & $\%$ & No. & $\%$ \\
\hline $\begin{array}{l}\text { Physiological changes } \\
\text { poor } \\
\text { Good } \\
\text { Very good }\end{array}$ & $\begin{array}{l}14 \\
16 \\
0\end{array}$ & $\begin{array}{l}46.7 \\
53.3 \\
0\end{array}$ & $\begin{array}{l}0 \\
6 \\
24\end{array}$ & $\begin{array}{l}0 \\
20 \\
80\end{array}$ & $\begin{array}{l}11 \\
19 \\
0\end{array}$ & $\begin{array}{l}36.7 \\
63.3 \\
0\end{array}$ & $\begin{array}{l}0 \\
5 \\
25\end{array}$ & $\begin{array}{l}0 \\
16.7 \\
83.3\end{array}$ \\
\hline $\begin{array}{l}\text { Special needs: } \\
\text { poor } \\
\text { Good } \\
\text { Very good }\end{array}$ & $\begin{array}{l}16 \\
13 \\
1\end{array}$ & $\begin{array}{l}53.3 \\
43.3 \\
3.3\end{array}$ & $\begin{array}{l}0 \\
6 \\
24 \\
\end{array}$ & $\begin{array}{l}0 \\
20 \\
80 \\
\end{array}$ & $\begin{array}{l}9 \\
21 \\
0 \\
\end{array}$ & $\begin{array}{l}30 \\
70 \\
0\end{array}$ & $\begin{array}{l}0 \\
3 \\
27\end{array}$ & $\begin{array}{l}0 \\
10 \\
90 \\
\end{array}$ \\
\hline $\begin{array}{l}\text { Abuse: } \\
\text { Poor } \\
\text { Good } \\
\text { Very good } \\
\end{array}$ & $\begin{array}{l}18 \\
12 \\
0 \\
\end{array}$ & $\begin{array}{l}60 \\
40 \\
0\end{array}$ & $\begin{array}{l}0 \\
4 \\
26 \\
\end{array}$ & $\begin{array}{l}0 \\
13.3 \\
86.7 \\
\end{array}$ & $\begin{array}{l}12 \\
18 \\
0 \\
\end{array}$ & $\begin{array}{l}40 \\
60 \\
0 \\
\end{array}$ & $\begin{array}{l}0 \\
4 \\
26 \\
\end{array}$ & $\begin{array}{l}0 \\
13.3 \\
86.7 \\
\end{array}$ \\
\hline $\begin{array}{l}\text { Total knowledge: } \\
\text { poor } \\
\text { Good } \\
\text { Very good }\end{array}$ & $\begin{array}{l}17 \\
13 \\
0\end{array}$ & $\begin{array}{l}56.7 \\
43.3 \\
0\end{array}$ & $\begin{array}{l}0 \\
6 \\
24\end{array}$ & $\begin{array}{l}0 \\
20 \\
80\end{array}$ & $\begin{array}{r}9 \\
21 \\
0\end{array}$ & $\begin{array}{l}30 \\
70 \\
0\end{array}$ & $\begin{array}{r}0 \\
3 \\
27\end{array}$ & $\begin{array}{r}0 \\
10 \\
90\end{array}$ \\
\hline
\end{tabular}

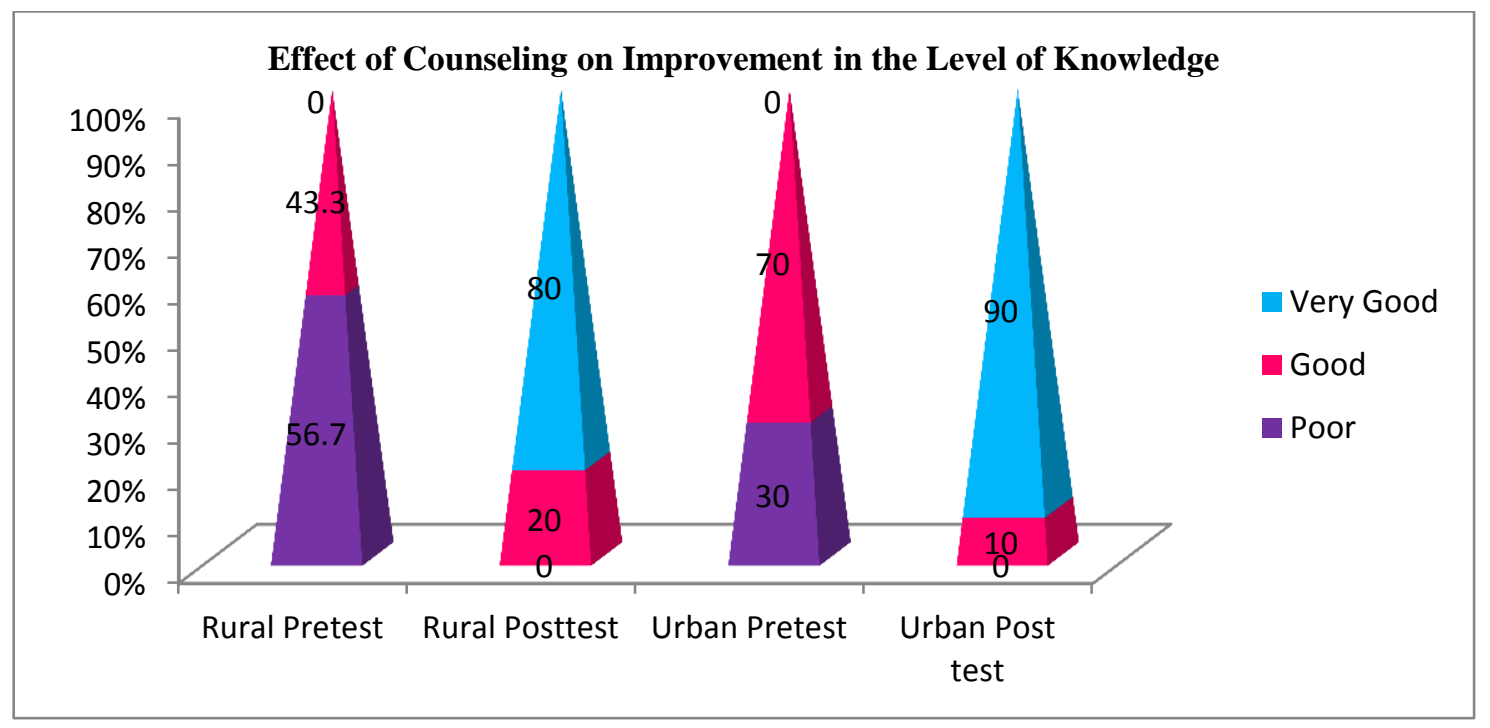

Figure 7: Effect of Counseling on Improvement in the Level of Knowledge among rural and urban caregivers of elderly between pre \& post test groups 
This figure depicts that $56.7 \%$ of the caregivers have poor level of knowledge in their pre test but $80 \%$ of the subjects got very good score during post test among rural area. Among urban, $30 \%$ have poor knowledge during pretest where as $90 \%$ got very good score during post test.

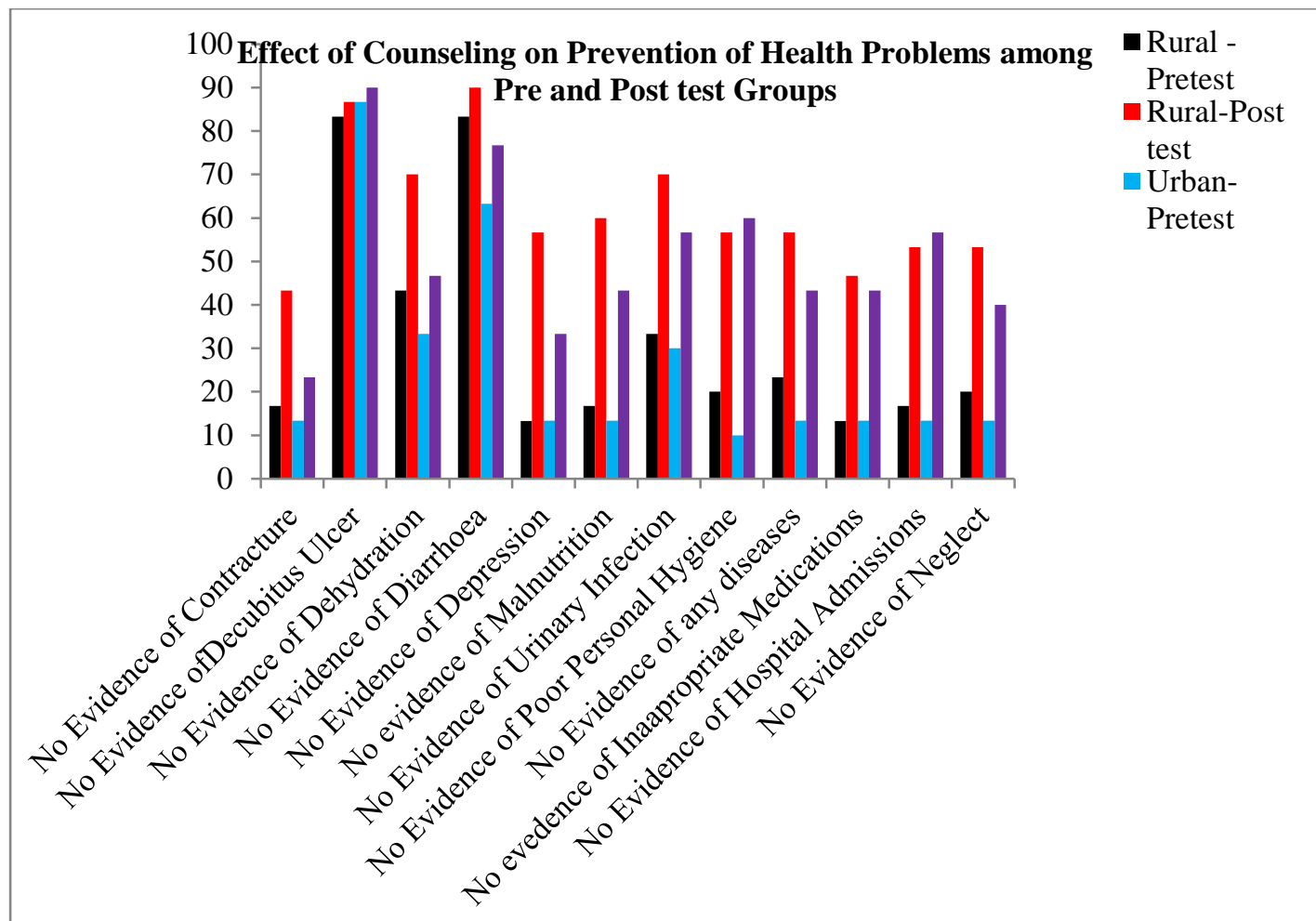

Figure 8: Effect of counseling on prevention of health problems among pre and post test groups of rural and urban areas.

This figure depicts that $13.4 \%$ have no evidence of self neglect during urban pre test, $46.7 \%$ have no evidence of dehydration during urban post test. , $83.3 \%$ have no evidence of diarrhea during rural pre test and $86.7 \%$ have no evidence of decubitus ulcer during rural post test.

Table 5: Association between Types of Abuse and Socio demographic Variables of Elderly

\begin{tabular}{|c|c|c|c|}
\hline Sl. No & Socio demographic variables & $\chi^{2}$ & P Value \\
\hline 1. & Gender & 4.5 & $>0.05$ \\
\hline 2. & Marital Status & 10.84 & $<\mathbf{0 . 0 0 1 *}$ \\
\hline 3. & Occupation & 7.67 & $>0.05$ \\
\hline 4. & Education & 8.45 & $>0.05$ \\
\hline
\end{tabular}

This table shows that there was a significant association between marital status and socio demographic variables of elderly.

Table 6: Association between Level of Knowledge and Socio- demographic Variables of Caregivers

\begin{tabular}{|c|c|c|c|}
\hline Sl. No & Socio demographic variables & $\chi^{\mathbf{2}}$ & P Value \\
\hline 1. & Gender & 0.027 & $>0.05$ \\
\hline 2. & Marital Status & 0.91 & $>0.05$ \\
\hline 3. & Relationship of Caregivers & 4.89 & $>0.05$ \\
\hline 4. & Occupation & 0.04 & $>0.05$ \\
\hline 5. & Education & 4.34 & $<\mathbf{0 . 0 5 ^ { * }}$ \\
\hline
\end{tabular}

This table shows that there was a significant association between education and level of knowledge of caregivers of elderly.

\section{Results}

1. Among 30 samples, $53.3 \%$ of the samples were male in rural areas, while $70 \%$ of the subjects were females in urban areas.

2. $60 \%$ of the subjects were married in rural areas but $60 \%$ of the subjects were widows in urban areas.

3. $50 \%$ of the subjects were unemployed in rural area but very few of them were employed in both areas. 
4. $60 \%$ of the subjects have the history of hypertension in rural areas and $33.3 \%$ of the urban samples were suffered from diabetes.

5. $73.3 \%$ of the samples were illiterate in rural areas but $53.2 \%$ of the subjects were illiterate in urban areas.

6. $100 \%$ of care givers were females in rural areas but $20 \%$ of care givers are males in urban areas.

7. $83.3 \%$ of the care givers were married in rural areas while $10 \%$ of the care givers are single in urban areas.

8. $70 \%$ of the care givers are unemployed in rural areas where as $53.3 \%$ of the care givers were employers in urban areas.

9. $33.3 \%$ of the care givers were illiterate in rural areas but $50 \%$ of the care givers are undergone University education in urban areas.

10. More than half of the care givers were daughter in-laws of both urban and rural areas.

11. Among 30 rural elderly, $33.3 \%$ have poor clothing, $36.7 \%$ have poor hygiene, $46.7 \%$ have problems of nutrition, $53.3 \%$ having skin problems during pre test but during post test they have good nutritional status $(73.3 \%)$ and good skin conditions $(63.3 \%)$.

12. Among 30 urban elderly, $30 \%$ have poor clothing, $33.3 \%$ have poor hygiene, $53.3 \%$ nutritional problems, $46.7 \%$ have skin problems during pre test but during post test they have good nutrition status $(56.7 \%)$ and good skin conditions $(66.7 \%)$.

13. Among rural elderly, $81 \%$ of the subjects were suffering from neglect, $69.3 \%$ have emotional problems $26 \%$ were the victims of financial abuse during pre test but $36.7 \%$ have self neglect and $10 \%$ have abandonment during post test.

14. $90 \%$ of the subjects were suffering from neglect, $86.7 \%$ have emotional problems, $63.3 \%$ were victims of financial abuse during pre test but, $43.3 \%$ have self neglect, during post test among urban elderly. This shows that abuses were common in urban than rural areas.

15. $56.7 \%$ of the caregivers have poor level of knowledge in their pre test but $80 \%$ of the subjects got very good score during post test among rural area. Among urban, $30 \%$ have poor knowledge during pretest where as $90 \%$ got very good score during post test. This finding shows that counseling has the significant role in improving the level of knowledge among post test groups of urban and rural care givers of elderly.

16. $13.4 \%$ have no evidence of self neglect during urban pre test, $46.7 \%$ have no evidence of dehydration during urban post test. $83.3 \%$ have no evidence of diarrhea during rural pre test and $86.7 \%$ have no evidence of decubitus ulcer during rural post test. This finding shows that counseling has the significant role in reduction of health problems of urban and rural elderly among post test groups.

17. There was a significant association between marital status and socio demographic variables of elderly.

18. There was a significant association between education and level of knowledge of caregivers of elderly.

\section{Discussion}

Elder abuse is an act or omission that results in harm or threatened harm to welfare of an older person ${ }^{10}$. Elder abuse is typically under-reported in most cultures. Prevalence rates/estimates exist only in selected developed countries - ranging from $1 \%$ to $10 \%{ }^{1}$. Therefore, the study aimed to determine the effect of counseling on elder abuse among elders and their care givers.

Regarding the Socio-demographic characteristics the results of the present study revealed that less than half of the subjects were females in rural areas, and about $70 \%$ of the subjects were females in urban areas, this finding is in consistent with the majority of the elderly in their studies were female ${ }^{11}$. Indeed, feminization of the older population has been observed globally and more so in the Philippines. In India majority of the elder populations are females. This phenomenon may be due to women having longer life expectancy by five to seven years than males, thus having tendency to outlive them ${ }^{12}$.

The results of the present study revealed that the majority of the subjects $(60 \%)$ were widow in urban area. This may be due to the fact that females in Egyptian culture are married younger than males so that the loss of a spouse is much more frequent for women than for men. This result is in agreement with who supported this analysis that many women can expect to live alone up to 20 years at the end of their lives compound with the fact that women in most culture marry men older than themselves, so that women have a longer life expectancy than men ${ }^{13}$. Women are live longer than men and therefore they are more likely to suffer the disabilities and illness associated with old age. Among people more than 60 years in developing regions, there are currently 88 men for every 100 women, but in developed country, where there are only 71 men for every 100 women over age $60{ }^{14}$. In India most of the elder females are widows ${ }^{15}$. 
The results showed that about half of the studied elderly were unemployed in rural areas while $70 \%$ of the subjects were unemployed in urban areas. In general high percentage of the elderly in both groups was unemployed. This is supported by the findings of $35.1 \%$ of elders were employed ${ }^{16}$. In India 55 million elderly sleep on an empty stomach every night. $75 \%$ of elders are reside in rural areas and more than two third of the Oldest Old $(80+)$ are financially dependent on others ${ }^{17}$. Thus, poverty is the greatest challenge to have a secured old age. According to the United Nations, worldwide only $30 \%$ of total elderly population is qualified for any form of pension and most of them are living in developed countries. With this reality, older people pursue their job for as long as physically able. In India financial problem is the most significant problem experienced by the elderly that is due to loss of job.

$73.3 \%$ of sample from rural areas were illiterate but $10 \%$ of the subjects from urban areas have secondary education. This result is supported with the illiteracy is prevailing between both groups in geriatric home and geriatric outpatient accounting for $60 \%$ and $48.3 \%$ respectively ${ }^{11}$. In India $33 \%$ of the older adults are below the poverty line and majority of them are illiterate ${ }^{17}$.

The current study showed that $60 \%$ of the studied elderly had history of hypertension and $13.3 \%$ had history of diabetes, $20 \%$ have heart diseases and $16.7 \%$ have chest diseases. This finding is consistent with the physical and mental impairment nevertheless appears to play an indirect role in elder abuse, decreasing seniors' ability to defend them or to escape, thus increasing vulnerability ${ }^{3}$. The risk of elder abuse becomes even greater when the caregiver is responsible for an older person who is sick or is physically or mentally impaired. Ageing is something that is irreversible and inevitable, as age increasing the body organs loses its ability to function well ${ }^{7}$. Majority of population of elderly in the Philippines usually suffer from loss of vision. Other disability like deafness, paralysis, memory loss and heart diseases which are now occurring at early age due to dietary changes has also been noted. In India it is estimated that by year 2015, nearly 7 Lakhs elderly in India will die of coronary Heart Diseases. 12 million people in India are blind out of this $70-80 \%$ of them are elderly. $62.6 \%$ are blind due to cataract ${ }^{17}$.

The present study finding shows that the majority of the caregivers in rural and urban area were female. This result is on the line with $62 \%$ of the caregiver in their studies was females, while males represented $38 \%$. These results may be due to the fact that in the Egyptian culture which stated that the burden of caring for parents rests upon the oldest son, daughter in-law has the responsibility in taking care of their old parents ${ }^{18}$. The age of caregivers ranged from 20-60 years ${ }^{19}$. The age of caregivers ranged from 18-62 years. Also, the results of the present study revealed that more than $83 \%$ were married. This is congruent with more than a half of the caregivers were married and majority of caregivers were daughter in-law ${ }^{18}$. Regarding relation of caregivers to elderly, the present study revealed that only $3.3 \%$ were relatives. This result is contradictory with the report stated that $60.9 \%$ of the caregivers were relatives ${ }^{8-9}$. Also the results show that one third and one fifth of the caregivers were illiterate in rural and urban area respectively. This result is in contradictory with the findings of $3.3 \%$ were illiterate ${ }^{18}$. Researcher's opinion is that may be due to the difference in level of education in developing and developed countries.

Regarding general assessment among elderly pre and post intervention in both groups, the present study clarified that a highly significant improvement in post counseling results compared to pre counseling $p>$ 0.001 in most of the items.

In addition to extensive counseling by the researcher about meaning of elderly neglect, forms, its signs and symptoms and special needs. This analysis supported that, education is the corner stone of preventing elder abuse, in which it educates caregivers about the special needs, problems of elderly and risk factors of abuse ${ }^{7}$. The study further revealed that $35 \%$ of them are experiencing disrespect as the most common form of abuse followed by verbal abuse (34\%) while $31 \%$ economic exploitation is the third most prevalent form of abuse among elderly. $31 \%$ of elders in India are abused by their relatives; the highest number of elder abused is traced in Madhya Pradesh with 77. $12 \%$. Every third senior citizen in India abused, mainly by son ${ }^{20}$.

Physical abuse, in many instances, is the easiest type of maltreatment to spot. It accounts for $20.1 \%$ of abuse allegations. Physical maltreatment may result in obvious injuries such as black eyes, welts over the body from objects used to hit an elder or from restraints at the wrists, ankles or waist ${ }^{11}$. The present study was not in accordance with the above statement which revealed that none of the elderly in the present study had physical abuse. Additionally, other studies contradictory with the result of the present study ${ }^{21}$. $28 \%$ of cases involved physical abuse, $25 \%$ of incidents were physical abuse. This is related to values, beliefs, religious and attitude in our community especially in rural area which forbidden physical abuse and also the idea of filial piety is still explicitly dominant in Egypt ${ }^{1,3,19}$. Physical abuse in the Philippines is $15.7 \%$ which is the second most common form of elderly abuse may be because of still having high regard and respect to elderly ${ }^{22}$. Sexual abuse accounts for $0.8 \%$ of abuse reports, and others reported that $0.3 \%$ was sexually abused ${ }^{23}$. This result disagrees with the present study which revealed that no elderly persons reported sexual abuse. This is may be due to attitude, values, beliefs and religious in our community especially in rural area which forbidden sexual abuse and also, the elderly are reluctant to report abuse. They are dependent on their abusive caregivers, and may be 
ashamed to admit what is happening to them. To the elderly person who is being victimized, the devil you know is often preferable to the devil you don't know ${ }^{3}$, also the perpetrators frequently feel ashamed and thus hide the incidents from investigators ${ }^{24}$. The report states that there have been $13 \%$ cases of abuse of elders reported in the state. Verbal abuse (observed as the main form of abuse) constituted $73 \%$ while physical abuse marked $27 \%$ 20

Findings of the present study indicated that about half of the studied elderly in urban area and about on third in rural area were financially abused. Congruent with the present results ${ }^{21}$. $51 \%$ of cases involved financial abuse, $27 \%$ of incidents were financially abused ${ }^{1} .30 .2 \%$ were financially abused and $39.2 \%$ of cases involved financial abuse ${ }^{3,16}$. In contradicting with the present study, financial maltreatment accounts for only $9.8 \%$ of abuse allegations ${ }^{25}$. Financial exploitation in Philippines accounts for $12.3 \%$. This may be due to poverty in our community whereas caregivers need money from elderly especially when they were unemployed and became dependent on elderly financially ${ }^{22}$. This analysis is supported by dependency is a contributing factor in elder abuse. When the caregiver is dependent financially on an impaired older person, there may be financial exploitation or abuse ${ }^{7}$.

When the reverse is true, and the impaired older person is completely dependent on the caregiver, the caregiver may experience resentment that leads to abusive behavior. The results revealed that majority of the studied subjects had psychological abuse $(88.3 \%)$, the emotional abuse was the most frequent type $(88.5 \%)$ of abuse among elders ${ }^{16} .68 \%$ of elderly adults having been psychologically abused ${ }^{26}$. Reports revealed that only $2.6 \%$ reported never using psychologically abusive behavior during the past 6 months, suggesting that most domestic caregivers demonstrated mild psychologically abusive behavior when dealing with their elderly care recipients ${ }^{19}$. Psychologically abusive behavior incidence was 1 to 7 times per week ${ }^{21}$. $87 \%$ of cases included psychological abuse ${ }^{3}$. Contradict to all the above results, psychological abuse may be one of the more difficult forms of maltreatment to recognize ${ }^{27}$.

Emotional abuse belittles elders and robs them of their dignity and self-respect. Abuse may be in the form of threats, intimidation and humiliation. 7.3\% emotionally abused among elderly Pilipinos. Psychological abuse may occur when an elder is isolated from duties or as an inheritance ${ }^{22}$. Researcher's opinion is that elders were upset with loneliness especially after death of their spouses, and also they felt with burden on their daughter in-law and caregiver's bad reaction toward their elderly i.e. they deal them as mad and surprisingly they consider their bad behavior is normal. Abuse of the elderly in developed countries has been reported in 1$10 \%$ prevalence of communities of elderly people, with psychological abuse being the most common type ${ }^{28}$. Psychological abuse was common category of abuse ${ }^{19}$. Verbal/psychological abuse was the most prevalent type ${ }^{11}$. Contradict to the above results, self-neglect $(41.9 \%)$ represents the highest number of reported allegations of elder mistreatment ${ }^{7}$. Neglect and financial abuse was the most prevalent type of abuse ${ }^{3},{ }^{24}$. The present study revealed that more than $75 \%$ of elderly were neglected by caregiver, consistent with findings of $49 \%$ of cases included neglect ${ }^{28,3}$. Caregiver neglect accounts for $13.2 \%$ of abuse allegations ${ }^{29}$. $7 \%$ of incidents were neglect ${ }^{30}$.

Frequently people who neglect themselves have dementia, chronic illness, or a substance abuse problem that interferes with their ability to safely manage their health and affairs. This is congruent with the present study which revealed that about two third of the studied elderly had self-neglect in both groups. This is may be due to highly percentage of depression, social isolation and chronic illness which appeared in results of the present study because depression, social isolation and chronic illness and poverty from the factors which leading to self-neglect ${ }^{7}$. There is a clear cut correlation between social support life satisfactions. As life satisfaction decreases, the risk for self-neglect increases ${ }^{31}$. Stated that self-neglect may escalate when paired with physical impairment, social isolation, malnutrition, substance abuse, cognitive impairment, and/or limited financial recourses. This study is also congruent with that the most common elderly abuse in the Philippines was neglect showing the highest percentage of $58.5 \%{ }^{22}$. Research has also shown that victims of elder abuse have had significantly higher levels of psychological distress and lower perceived self-efficacy than older adults who have not been victimized. ${ }^{29}$ In addition, older adults who are victims of violence have additional health care problems than other older adults, including increased bone or joint problems, digestive problems, depression or anxiety, chronic pain, high blood pressure, and heart problems.

The current study indicated that the percentage of elderly abuse in urban area was more than $75 \%$ while the percentage of elderly abuse in rural area was less than $75 \%$. This analysis is in agreement with the statement of lack of family ties, a culture of family violence are risk factors for abuse in the victim ${ }^{21}$.

Finding of this study revealed that financial abuse and abandonment was less than one third in rural area while in urban area financial abuse was two thirds and abandonment more than half with highly significant difference. This is may be due to lack of family ties and social support which make caregiver to leave elderly alone without supervision in urban area which lead to abandonment. Also financial abuse in urban area was high due to people in urban area need more money to live than rural area so engagement in financial abuse 7 . Caregiver is dependent financially on an impaired older person; there may be financial exploitation or abuse. 
The results of the present study revealed that $75 \%$ of the studied elderly had elderly abuse ${ }^{32}$. $4-10 \%$ of older persons were experiencing abuse of some kind ${ }^{10}$.

The current study clarified that knowledge of elderly after intervention more than half had very good knowledge while knowledge of caregivers after intervention more than three quarters had very good knowledge i.e. improvement on knowledge of caregivers high than elderly. This may be due to level of education high among caregivers also to other reason because the posttest made after three months from the counseling and elderly had good remote memory than recent memory.

There was no gender difference in the prevalence of elder abuse ${ }^{33}$. This result disagrees with the report shows that two thirds of victims of abuse were woman ${ }^{11}$. In other hand that the majority of elder abuses among females ${ }^{23}$.

Also results of the present study revealed that there was significant difference between total abuse and marital status. The current study showed that there was no significant difference between total abuse and level of education and age of elderly. This is supported that no significant correlation between abuse and level of education and age of elderly ${ }^{19}$.

The present study also found that no significant difference between total abuse and occupation. This is disagreeing with the statement of statistical significance relationship between elder abuse and occupation ${ }^{16}$. Unemployment is risk of abuse. Finding of this study has shown that there was significant difference between total knowledge of elderly and gender i.e. male had high knowledge than female. This is may be due to level of education was high in males than female because families not interested by educating female and also male had job than female and this make male had experience and knowledge than female ${ }^{23}$.

In addition, finding of this study has shown that there was significant difference between total knowledge of elderly and marital status i.e. married persons had knowledge than single, widow and divorced whereas persons who married make relation with other and earns more experience and knowledge. Regarding occupation as a factor in total knowledge of elderly. The results of the present study showed that there was significant difference between total knowledge of elderly and occupation i.e. knowledge high among employed persons than unemployed because employed persons had experience and level of knowledge than unemployed persons. In addition, findings of this study has shown that there was significant difference between total knowledge of elderly and education i.e. level of knowledge was high among educated people than illiterate because the more education more knowledge.

Concept of elder abuse as relevant to the developed world is alien to the Indian society. The Indian scenario is not individualistic but a traditional family based society where the older persons still seem to be considered a respected lot. Due to technical advances and migration from rural to urban areas, the roles of older people have become ill defined and too insignificant for the family ${ }^{15}$.

The present study indicated that there was no significant relation between abusive behavior and gender of caregivers. This may be due to the small numbers of the sample. This disagrees with that the level of abusive behavior was positively correlated with gender i.e. female caregivers are more abusive than their male counterparts ${ }^{19}$. This gender difference can be explained by cultural norm that expects women to be the primary caregivers of dependent family members, and consequently women are more socially isolated as a result of this role. Isolation associated with caring for an elderly person can produce high level of anxiety, depression, and stress. Thus female caregivers may be at high risk for becoming abusers ${ }^{27-28}$.

The results of the present study found that there was significant relation between abusive behavior and level of education of caregivers. This is consistent with the level of abusive behavior was positively correlated with level of education. Elderly abuse was high in caregivers with higher level of education than the caregivers with lower level of education. Level of abusive behavior was correlated with relation of caregiver to elderly ${ }^{19}$. This findings was disagreed with the results of the present study where found that there was no significant relation between abusive behavior and relation of caregiver to elderly. The results illustrated that there was negative relation between ages of caregivers and total knowledge of caregivers i.e. when age of caregiver's decreased, total knowledge of caregivers increased. This may be due to younger people have high level of education than old age.

The results also indicated that there was significant difference between knowledge of caregivers and occupation of caregivers where knowledge level of caregivers was high among employers than unemployers. The elderly and their care givers have poor knowledge on abuses, the rate of abuse was very high while, the good knowledge of elderly and their caregivers, and elderly abuse was less. So, the present study aims at identifying impact of counseling for elders and their caregivers on reduction of elderly abuse. 


\section{Conclusion}

In conclusion, in the light of the present study findings, there was a significant improvement in knowledge of elderly and their caregivers regarding prevention of abuses. Due to the effect of counseling, there was a significant reduction in neglect and abandonment among elderly in post test groups.

Based on the findings of the present study, it could be recommended that:

- Community Health Nurse should intervene in relationships between the elderly and their caregivers and contribute to interdisciplinary collaboration efforts to solve problems of elderly abuse.

- Community Health Nurse should offer counseling services for the victims of elder abuse including family counseling, conflict resolution, assertiveness training, grief and loss, and depression and suicidal thinking.

- Develop a screening and assessment tool on elder abuse for early identification of abuse cases from the primary health care setting.

- Support and promote those who are in risk or experiencing any types of abuses.

- A media campaign be carried out that is aimed at raising community awareness about the rights of older adults and protection of elder person from elder abuse.

- Collaboration of local organizations with policy makers to strict implementations of rules and regulations to prevent elder abuse.

- Formulate Abuse Prevention Cell for the Elderly, which includes, Community Health Nurses, Doctors, Social Worker, Psychologist and Policeman.

- Develop Health Awareness program on "Assertive Training for the Elders \& their care givers"

- Formulate Guideline on Legal protection of Elders \& Prevention of Abuse

\section{Acknowledgement}

The authors are grateful to all the elders and their caregivers who participated in the study. The authors also wish to thank Almighty God for accomplishment of this research work.

\section{References}

[1]. World Health Organization (2011). Prevention the Elder Abuse at: www.Who.int/aging/projects/elder-abuse/en/index.html (2002).

[2]. Choi and Mayer, T . (2000). Elder abuse neglect, and exploitation, risk factors and prevention strategies. j. Geronotol. soc . sci;33: $5-25$

[3]. National center of Elder Abuse. (2011). frequently asked questions) at Washington, DC. NCEA (2011). Frequently asked question at washing ton. DC. At

[4]. United Nations Department of Social and Economic Affairs Population Division. ( 2004). World Population Prospects: the 2004 revision. New York, United Nations, 2002.

[5]. National Center on elder abuse. (2002). Preventing elder abuse by family caregiver Washington. B. C. the institute on aging. Nerenberg. L. (2002) caregiver stress and elder abuse. AT.

[6]. Mansour, E. (2001). Counseling. In: Interpersonal communication, counseling and client education. Protocol for nurses in Cairo, Egypt September 2001.pp.35.

[7]. American psychological association. (2011). Elder abuse and neglect. At http//www.apa.org/pi/aging/eldabuse.html

[8]. Allender, J., A and Spradly, B.W. (2001). Mistreatment of elders in: community health nursing .5th edition .Lippincott. New yank. pp 500-501.

[9]. International council of nurses. (2011). Elder abuse. At. http://www.icn.ch/matters - elder - print htm

[10]. Abuo Baker, O., Mahmoud, S., \&Mostafa, N. (2006). Psychosocial assessment of institutionalized elderly in geriatric homes .Sc.J.Med.Fac.(Girls). Vol.27. No.3, Sep, 2006: 2013-2029.

[11]. American Association of Retired Persons and the Administration of Aging. (2003). The aging process At http: //WWW.aoa.dhhs.gov/aoa/stata/profile/

[12]. Baker, MW., and Heitkemper, MM. (2005). The roles of nurses on interprofessional teams to combat elder mistreatment. Nurs. Outlook 2005; 53: $253-9$.

[13]. Walton, J. (2001). Community health nursing concepts and practice, $5^{\text {th }} \mathrm{E}$ d., USA, Lippincott comp, pp $608 \mathrm{n}-613$.

[14]. Multnoomah Country adult and aging services. (2007). Understanding and dealing with elder abuse. Atwww.oregoncounseling.org/.../ElderAbuse.htm

[15]. World Health Organization Report on Elder Abuse, Indian Studies , 2013

[16]. Khattab, M., Fahmy, M., Elgammal, H. and Soltan, E. (2009). Frequency and risk factors of the elders in the university hospital and health insurance attendance in Ismailia city. Egypt. Med. J of Cairo Univ.; Vol., No. , Presented in the Annual Family Medicine Department Conference [Challenges of Chronic Diseases in Family Medicine] held in October 7-8, 2009.

[17]. Help Age India-2013 Reports http://www.helpageindia.org/helpageprd/index.php?option=com issue\&view=issue\&Itemid=7

[18]. Wang, J. (2005). Psychological abuse and its characteristics correlates among elderly Taiwanese gerontology \& geriatrics; 42(3): 307-318.

[19]. Wang, J., Ni Lin, J., and Ping Lee, . F. (2006). Psychologically abusive behavior by those caring for in elderly domestic context. Geriatrics Nursing; 27(5): 284-291.

[20]. Every third senior citizen in India abused, mainly by son: StudyReport on elder Abuse, Times of India-2013

[21]. Gallo, J., Bogner, H. R., Fulmer, T., and Paveza, BJ. (2006). Handbook of Geriatric Assessment, (2006). Boston, Toronto, London.

[22]. Cua , Philip., (2013). http://newsinfo.inquirer.net/399241/elder-abuse\#ixzz2jbcIzDJi 
[23]. National center on elder abuse. (2011). Risk factors for elder abuse. At Washington.D C. at national association of state units on aging. At www.used.edu/elderlaw/archives/ elder-abuse -in-society.htm.

[24]. Mauk,K. (2006). Competencies for care in: gerontological nursing. Isted.Boston, TornotoandLondon.

[25]. Jamuna D. Issues of elder care and elder abuse in the Indian context. J Ageing Soc Policy 2003; 152: 125-42.. Available from: http://www.who.int/healthinfo/survey/ageingdefnolder/en/index.html. [last accessed on 2009 May 15].

[26]. El Ganzoury, G., Osman, A., \& Othman, O. (2002). Effects of counseling on patterns of care and life burden on family caregivers of schizophrenic patients.

[27]. Benedictis, T.,Jaffe, J., and Segal, J. (2010). Elder abuse At www.Helpguide.org

[28]. Siegal- Itzkovich, J.A (2005). Fifth of elderly people in Israel are abused. British Medical Journal, $2005,330: 498$.

[29]. Teaster, P. et al. (2000). Sexual Abuse of Older Adults: Preliminary Findings of Cases in Virginia. Journal of Elder Abuse \& Neglect. Vol. 12, No. 3/4, $1-16$.

[30]. Fulmer, T. (2003). Elder abuse and neglect assessment. Journal of Gerontological nursing;29(1): 8-9

[31]. Haight, B., and Gibson, F. (2005). Group process and techniques in: working with older adults. $4^{\text {th }}$ ed. Boston. Toronto. Jones and Barllet publishers.

[32]. Blonna, R., and Watter, D. (2005). What is counseling in: introduction to counseling? Jones and Bartlett puplisher. Boston, London and Toronto. Gohnpow company. Pp.1-15

[33]. Ivey, A., and Ivey, M. (2003). Intentional interviewing and counseling facilitating client development in a multicultural society. Pacific grove,CA: brooks cole

[34]. Med.J. Cairo Univ., Vol. 70. No.3, Sep, 2002: 543-552.

[35]. Wilson, J. (2007). Is it elder abuse. At Caregiver.com 